\title{
DETERMINANTS OF RURAL RETAIL TRADE: A CASE STUDY OF ILLINOIS
}

\author{
John J. Gruidl and Dimitri Andrianacos*
}

\begin{abstract}
This study examines the determinants of retail trade capture in nonmetropoliten counties in Illinois using pooled time series and cross-section datn from 1984 to 1989. By controlling for fixed effects, the approsch avoids misspecification, while revealing trade patterns through time. The findings indicate that demand plays a central role in rural trade. However, the results suggest that structural elements (such as market access and shopping center development) are important and changing over time to the detriment of rural areas.
\end{abstract}

\section{INTRODUCTION}

Retail trade shifted away from many rural (nonmetropolitan) areas during the 1980s, as documented by several analysts (e.g., Senf 1988 in Minnesota, Yanagida et al. 1991 in Nebraska, and Darling and Tan 1990 in Kansas). Urban areas, in particular suburbs, gained market share (Schneider 1992). Illinois is no exception to these trends. In Illinois, the share of total retail sales captured by nonmetropolitan counties declined from 15.8 percent in 1984 to 13.6 percent in 1989 (IIlinois Department of Revenue).

This decline raises concems about the vitality of retail businesses in rural areas, particularly in smaller communities. This issue is crucial, since retail trade is the second largest employment sector nationally, representing nearly 18 percent of total 1990 employment (U.S. Council of Economic Advisors 1992). Furthermore, in states where local governments receive sales taxes revenue, a smaller retail sector shrinks the tax base, forcing local governments to either reduce services or find altemative funding sources.

Many factors contribute to declining market share in rural areas including population loss and declining purchasing power, improved highway travel, increased work-related commuting, and expansion of regional shopping malls. Stone (1989) emphasized the role of regional discount stores in realigning rural trade patterns in lowa.

A better understanding of the forces influencing retail markets in rural communities is important for public policy efforts to revitalize rural trade. If declines in trade result from structural factors, such as improved highway accessibility or

\footnotetext{
*Assistant Professor in the Illinois Institute for Rural Affairs, and Assistant Professor in the Economics Department, Western Illinois University, respectively. The authors thank Norman Walzer for comments on an earlier version.
} 
competition from new retail outlets (i.e., regional discount stores), efforts to improve the competitiveness of rural retailers may prove successful. On the other hand, if demand, reflected by declining population and per capita income, is the primary factor, significant retail improvement is unlikely without broader economic development efforts aimed at expanding basic employment and income.

This paper examines determinants of retail trade capture in nonmetropolitan Ilinois counties based on a pooled sample of annual time series and cross-sectional observations from 1984 to 1989 . The model controls fixed effects, such as distance to a neighboring trade center, while investigating demand and supply variables that change through time. The analysis also investigates the impact of regional discount stores on retail sales in rural areas, a factor not usually included in previous studies.

Trends in Illinois retail trade are presented in the next section, followed by a summary of previous research on determinants of retail trade. The conceptual framework follows, motivating the specification of the econometric model. The final sections present the methodology and results of the model, with special attention paid to variables that influence trade capture.

\section{TRENDS IN ILLINOIS RETAIL TRADE}

The economy of Illinois is dominated by the Chicago Consolidated Metropolitan Statistical Area (CMSA), consisting of Cook County and seven collar counties (Figure 1). However, 36 percent of 1990 Illinois population and 30 percent of employment are located in downstate Illinois, outside the Chicago CMSA. There are 76 rural (nonmetropolitan) counties and seven metropolitan areas in downstate Illinois. Rural economies generally performed poorly and lagged urban counties in the 1980 s. Only six of the rural counties gained population in the 1980s. The economic base of many rural communities is threatened by employment losses in manufacturing, mining, and farming.

Trends in Illinois retail trade patterns from 1984 to 1989 mirror income changes (Table 1). Real growth in per capita incomes is highest in the collar counties, which experienced the most rapid sales growth. In contrast, nonmetropolitan areas had the slowest income growth and an actual decline in real sales. The effect was a shift in market share to the collar counties, largely at the expense of the nonmetropolitan counties. The market shares of Cook County (Chicago) and the downstate cities declined only slightly. This is consistent with a national pattem of suburbanization of retail trade (Schneider 1992). 


\section{FIGURE 1}

\section{Classification of Ilinois Counties}

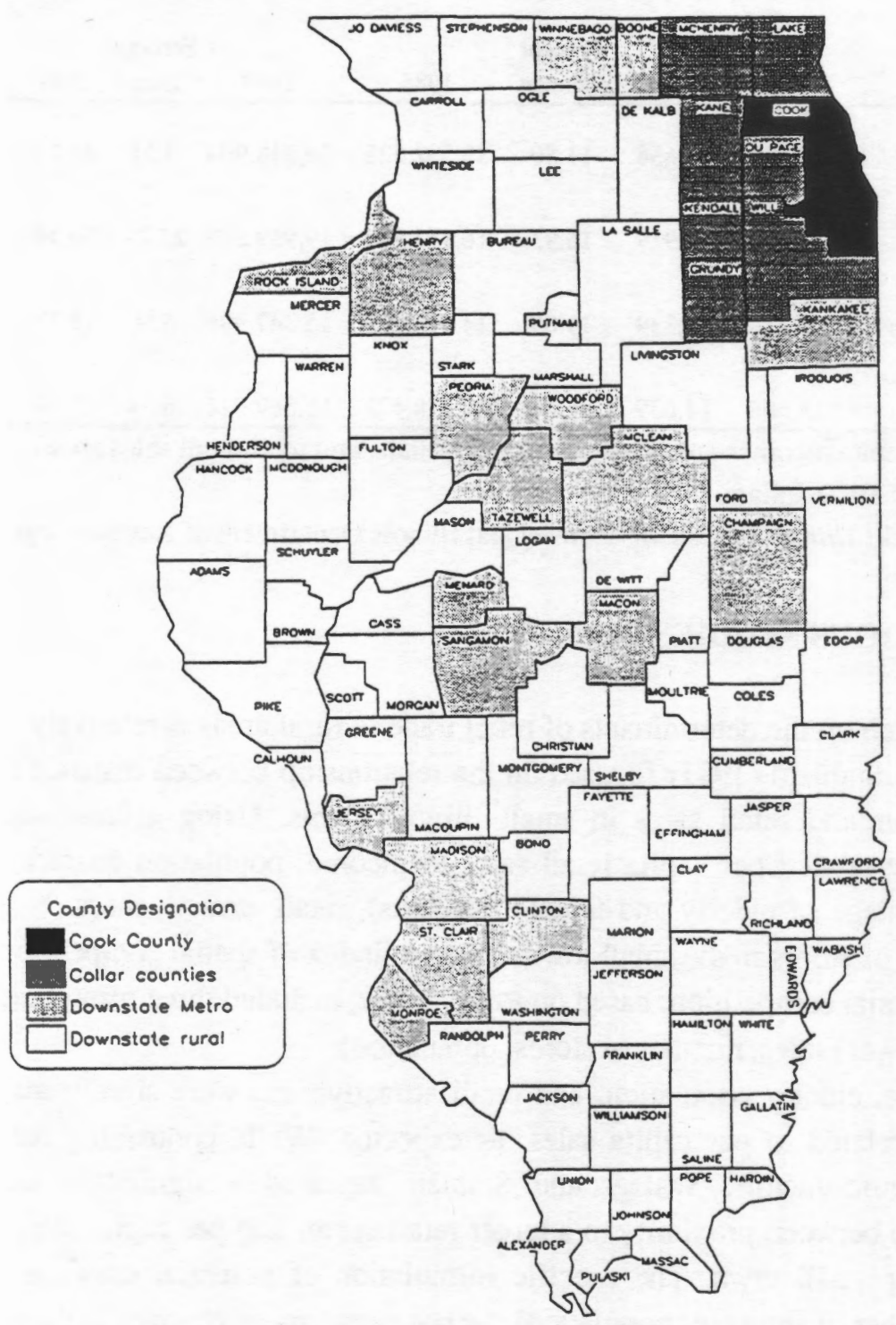

Source: U.S. Department of Agriculture, Economic Research Service. 


\section{TABLE 1}

Income and Retail Sales in nlinois Counties, 1984-89

\begin{tabular}{|c|c|c|c|c|c|c|c|c|}
\hline \multirow[b]{2}{*}{ Region } & \multicolumn{3}{|c|}{ Per Capita Income } & \multicolumn{3}{|c|}{ Total Retrail Sales } & \multicolumn{2}{|c|}{$\begin{array}{c}\text { Percent } \\
\text { of State } \\
\text { Retail Sales } \\
\end{array}$} \\
\hline & 1984 & 1989 & $\begin{array}{l}\text { Percent } \\
\text { Change }\end{array}$ & 1984 & 1989 & $\begin{array}{l}\text { Percent } \\
\text { Change }\end{array}$ & 1984 & 1989 \\
\hline Cook County & 17,630 & 19,658 & 11.50 & $35,532,528$ & $38,218,904$ & 7.56 & 45.29 & 44.91 \\
\hline $\begin{array}{l}\text { Coller } \\
\text { counties }\end{array}$ & 18,045 & 20,919 & 15.93 & $16,133,399$ & $19,959,528$ & 23.72 & 20.56 & 23.46 \\
\hline $\begin{array}{l}\text { Downstate } \\
\text { metropolitan }\end{array}$ & 14,713 & 16,339 & 11.05 & $14,411,729$ & $15,347,996$ & 6.50 & 18.37 & 18.04 \\
\hline $\begin{array}{c}\text { Downstate non- } \\
\text { metropolitan }\end{array}$ & 13,508 & 14,639 & 8.38 & $12,378,422$ & $11,569,024$ & -6.54 & 15.78 & 13.59 \\
\hline
\end{tabular}

\section{PREVIOUS STUDIES}

Research on the determinants of retail trade in rural areas is relatively sparse. Walzer and Stablein (1981) focused on the relationship between distance from a major center and retail sales in small Illinois towns. Using a cross-sectional model, they related per capita retail sales to income, population characteristics (i.e., percentage of elderly and female residents), retail attractiveness (based on the number of stores in the small towns), and an index of spatial competition. The index of spatial competition, based on Reilly's law, included three formulations of drawing power (sales, number of stores, population).

Income, elderly population, and retail attractiveness were significantly and positively related to per capita sales, as expected. While controlling for these socioeconomic factors, Walzer and Stablein reported a significant negative relationship between proximity to a larger retail center and per capita sales in the neighboring small town. The specific formulation of potential drawing power (sales, number of stores, or population) did not cause major changes in the results, causing them to conclude that "the magnetism of nearby cities was quite strong" (Walzer and Stablein 1981, 8).

Yanagida et al. (1991) examined factors affecting retail trade in Nebraska counties, employing pull factors as a measure of retail capture. Using a cross-sectional model for each of the years 1975,1980 , and 1985, they related pull factors 
to income, population, age distribution, number of retail outlets, and linear distance to the nearest trade center (city with a population of at least 10,000). Their findings were consistent with those of Walzer and Stablein in that income and population were positively and significantly related to pull factors. Concentration of elderly population was also positively and significantly related in some formulations. Distance to a trade center was an significant explanatory factor, with increasing distance positively associated with pull factor.

Other studies have focused on the impact of sales tax differentials on retail sales (Love 1992; Walsh and Jones 1988) and on tax revenues (Snodgrass and Otto 1990). For example, Love examined the impact of sales tax differentials on retail sales in south Georgia counties with a pooled sample of annual time series and cross-sectional data from 1980 to 1989 . The model related per capita sales to sales tax differentials between counties, income, number of establishments, and retail market area. Computation of retail market area was based on the average distance to neighboring cities of at least 10,000 . Love reported that both income and number of establishments were directly and significantly related to per capita sales. The market area variable and sales tax differential were significant and inversely related to sales.

Generally, results of previous studies are consistent in that socioeconomic factors (e.g., population and income) and market area (distance to other trading centers) are critical determinants of retail sales. None of these studies includes regional discount stores as possible trade determinants, in spite of Stone's (1989) findings. With few exceptions (such as Love), these studies have used cross-sectional data, which does not reveal changes in trade patterns over time. Furthermore, since it is virtually impossible to control for all cross-sectional differences that affect retail trade (for example, market access, demographic characteristics, transportation networks), OLS estimates using cross-sectional data are likely to be biased. A pooled data approach that controls for fixed effects, including cross-sectional differences, provides more reliable estimates.

\section{EMPIRICAL MODEL}

Central place theory provides a conceptual framework for understanding trade pattems (e.g., Christaller 1966). Each good has a threshold demand (the minimum quantity a supplier must sell in order to earn at least normal profits). It is advantageous for businesses with similar threshold sizes to serve the same market area because of agglomeration economies. When businesses concentrate at the center of a particular market area, central places form (Blair 1991). 
Central place theory postulates the existence of an ordering or hierarchy of trade centers. Higher ranks in the hierarchy are distinguished by increasing sales volume, range of available retail goods, size of market areas, and number of retail establishments. The hierarchical structure changes as market sizes change. If market sizes increase, the site of retail goods will shift upward, and lower-order central places are weakened compared to larger cities. In tum, market size depends on the interaction of demand and supply forces.

Declining retail sales in small rural communities are explained by factors that increase market sizes. Shrinking population experienced in many rural communities, if not compensated by increases in per capita income, reduces demand density. Market sizes expand to meet demand thresholds, meaning that small rural communities lose trade to larger places. Furthermore, better highway access to rural communities reduces transportation time and costs, increasing market sizes and weakening small rural trade centers.

Increased economies of scale for retail goods have the effect of enlarging trade areas and concentrating the activity in fewer large places. The modem shopping center and regional discount stores add to the competitive position of larger central places. Improvements in technology have a role in increasing economies of scale. Stone (1988) attributes the low operating costs of regional discount stores, in part, to adoption of technology in distribution and inventory control.

Conceptually, this study models retail trade in a community as a function of factors affecting demand and supply of retail goods. The pull factor, a frequently used measure of retail trade activity, is the dependent variable and has the advantage of correcting for population and price changes, as expressed in the following equation (Hustedde, Shaffer, and Pulver 1984).

$$
P F_{i}=\frac{\frac{S A L E S_{i}}{S P C E}}{P O P_{i}}
$$

where $P F_{i}=$ pull factor for community $i$,

$$
\begin{aligned}
& \text { SALES } i=\text { total retail sales for community } i \\
& \text { SPCE } \\
& \text { POP } i=\text { downstate per capita expenditures for retail goods, } \\
& \text { Population of community } i \text {. }
\end{aligned}
$$

The pull factor represents an equivalent number of customers served in a community divided by the community's population. ${ }^{1}$ A pull factor of less than one indicates that the community is attracting fewer customers than its population and/or that per capita spending by local residents is less than the downstate 
average. When the pull factor is more than one, the community captures customers from outside its borders and/or local residents spend more per capita than the downstate average.

Demand variables. A community's sales of goods and services depend on the size and strength of the local economy. Population, income, and the unemployment rate are included as demand variables. Higher population (POP) indicates a community of higher order in the hierarchy with larger market areas and higher sales. Per capita income (INC) reflects average purchasing power in the community and is expected to be positively associated with pull factors. The unemployment rate (UR) indicates the pool of residents with limited purchasing capacity. Unemployment rate (UR) is expected to be inversely related to pull factors, since unemployed residents postpone purchases. Since pull factors depend on per capita sales in a community relative to the downstate average, it is the relative level of these variables compared with other communities, rather than their absolute level, that is critical in determining pull factors. ${ }^{2}$ Therefore, each of the demand variables is specified relative to its corresponding downstate value.

Demand also depends on relative prices with respect to prices of goods sold in neighboring communities. Previous studies use distance to neighboring cities as a proxy for relative prices of local and non-local goods. Since the econometric model used in this study controls for fixed effects, such as distance to a neighboring city, a market area variable is not explicitly introduced into the model.

Supply variables. The supply of retail goods is a function of the number of outlets (STORES). The number of stores reflects the variety of offerings in a community, with variety being an important dimension of competitive advantage. As a proxy for the attractiveness of the community as a shopping destination, the number of stores is expected to be positively related to pull factor. The number of regional discount stores (DISC) is also considered a determinant of supply. The number of discount stores is an indicator of an important structural change in retailing-the proliferation of regional discount stores into rural areas. Stone (1988) reported that regional discount stores attracted customers from neighboring communities, thus boosting trade. Furthermore, the number of discount stores may reflect economies of scale that are expected to widen market areas, concentrating trade in larger centers. A positive relationship between the number of regional discount stores and pull factor is expected.

Incorporating both demand and supply variables yields the following empirical model:

$P F=f(I N C$, POP, UR, STORES, DISC) 
where $P F=$ pull factor,

INC = per capita income relative to the downstate average,
POP $=$ population relative to downstate population,
UR $=$ unemployment rate relative to the downstate average,
STORES = number of retail stores,
DISC $=$ number of regional discount stores.

Annual data for pull factors and independent variables were compiled for IIlinois nonmetropolitan counties for the period 1984 to 1989. Although municipalities are preferred to counties as a unit of analysis, municipal data for many independent variables are not available for consecutive years. Retail sales are based on sales tax reports from the Illinois Department of Revenue. Due to changes in reporting, comparable sales tax data are not available prior to 1984. The tax data were converted into retail sales by using the appropriate sales tax rate. Some goods are exempt from sales tax (including farm purchases and some food items). Taxed items, however, account for the predominant share of Illinois retail sales.

Data on the number of retail outlets and the number of regional discount stores (more than 50,000 square feet) were also obtained from the Illinois Department of Revenue. Data for population, income, and unemployment rate were obtained from the 1991 Illinois Statistical Abstract.

\section{METHOD}

To analyze the variables that affect pull factors, this study pools annual data for all 76 nonmetropolitan Illinois counties for the period 1984-1989. The main advantage of pooled cross-section and time series data is the potential for capturing variation across different units in space as well as variation that emerges through time. Pooled data is particularly useful in the present case, given the short length of the time series and modest size of the cross sections.

A challenge in using pooled data is specifying a model that adequately allows for differences in behavior over cross-sectional units as well as differences in behavior over time for a given cross-sectional unit. Standard regression analysis requires the assumption that regression parameters are constant across space and time. This means that the relationship between the dependent and independent variables, and therefore the regression coefficients, are the same for all cross sections and time periods. Since this assumption is usually unrealistic, the 
OLS estimates of pooled data are likely to be both biased and inefficient (Nerlove 1979).

The fixed effects or covariance model captures the differences among different cross sections and time periods and avoids misspecification. The fixed effects model is frequently used when dealing with pooled cross-section and time series observations and is within the framework of the classical regression. With the fixed effects model, each cross section and time period has its own special intercept, although they share a common slope. ${ }^{3}$ By incorporating binary (dummy) variables in the regression equation, the intercept term is allowed to vary over time and over cross-section units. ${ }^{4}$

The following two-way (time and cross-sectional effects) model is estimated:

$$
P F_{i t}=\alpha+\alpha_{i}+\gamma_{t}+\beta^{\prime} X_{i t}+\epsilon_{i t}
$$

Where, PF is the pull factor,

$\alpha \quad$ is the overall constant of the model,
$\begin{aligned} & \alpha \\ & \alpha_{i}\end{aligned}$ is a dummy variable that represents the cross-section
(county) effect,
$\gamma_{\text {is a dummy variable that represents the time effect, }}$
$X \quad$ a vector of $K=5$ explanatory variables (INC, POP, UR,
STORES, DISC), and
$\beta^{\prime} \quad$ is a vector of the slope coefficients of the explanatory
variables that are assumed constant over time and
cross sections (counties).
$\Sigma \alpha_{j}=0, \Sigma \gamma_{t}=0$ to avoid multicollinearity,

There are $N=76$ cross sections (counties) and $T=6$ time periods (years) in the data. The disturbance $\epsilon_{i t}$ is assumed to satisfy the assumptions of the classical linear regression model. Equation (2) contains $K+(N-1)+(T-1)=85$ regression coefficients to be estimated from NxT $=\mathbf{4 5 6}$ observations. If the model is correctly specified and the classical assumptions are satisfied, the ordinary least squares estimates of the regression coefficients are unbiased and efficient. ${ }^{5}$

The reasoning behind the fixed effects model is that in specifying the regression model, we have failed to include a group of relevant explanatory variables that do not change over time and others that do change over time but have the same value for all counties. Therefore, each county and each time period are characterized by its own specific intercepts. This feature is incorporated into the regression model by dummy variables. The inclusion of dummy variables "covers up" our lack of information. ${ }^{6}$ 


\section{EMPIRICAL RESULTS}

Table 2 presents the fixed effects model estimates under different sets of assumptions and also presents coefficient values and their marginal probability values for model (1) and model (2). Model (1) includes county effects; it assumes

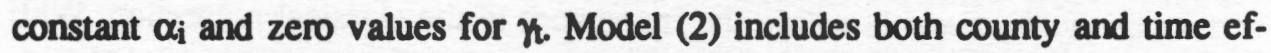
fects; it assumes that both $\alpha_{i}$ and $\gamma_{t}$ are constants. In the lower portion of Table 2 , summary statistics are presented for models (3) and (4). Model (3) is an OLS regression with no county or time effects. Finally, model (4) includes time effects; assumes zero values for $\alpha_{i}$ and constant $\gamma_{\text {. }}$.

TABLE 2

Estimation of Pull Factor Models

\begin{tabular}{lcc}
\hline \hline & $\begin{array}{c}\text { Model (1): } \\
\text { OLS with X-Variables } \\
\text { and County Effects }\end{array}$ & $\begin{array}{c}\text { Model (2): } \\
\text { OLS with X-Variables and } \\
\text { County and Time Effects }\end{array}$ \\
\hline Independent Variable & Coefficient & Coefficient \\
Per capita income & .9285 & .3690 \\
Population & $(.00)$ & $(.02)$ \\
Unemployment rate & 467.7 & 197.0 \\
& $(.00)$ & $(.04)$ \\
Retail stores & -.101 & -.075 \\
& $(.00)$ & $(.00)$ \\
Discount stores & .0004 & .0003 \\
& $(.03)$ & $(.18)$ \\
Constant & .0098 & .0271 \\
& $(.53)$ & $(.07)$ \\
&..- & -.116 \\
&.- & $(.66)$ \\
& & $\mathbf{R}^{2}=.95$ \\
& $\mathbf{R}^{2}=.94$ & $\mathrm{Adj}-\mathbf{R}^{2}=.94$ \\
\hline
\end{tabular}

Model (3):

OLS with X-variables only

$\mathbf{R}^{2}=.41 \quad$ Adj- $\mathbf{R}^{2}=.41$
Model (4):

OLS with X-variables and time effects

$\mathrm{R}^{2}=.44$ Adj-R $R^{2}=.43$

Note: Numbers in parenthesis under coefficients represent p-values. 
It is apparent that county effects are important in explaining pull factors. Model (1), which includes county effects, explains 94 percent of the variation in pull factors, considerably higher than model (3) (41 percent) or model (4) (43 percent). Model (2), which includes both county and time effects, increases explanatory power only slightly over model (1).

A series of tests determine which of the four models is most appropriate. The first test is whether different counties have different intercepts. If they do not have different intercepts, then more efficient estimates are obtained by treating the data as one sample with 456 observations, model (3). Under the null hypothesis that there are no other county effects that explain the pull factors, $\left(\mathrm{H}_{0}: \alpha_{1}=\alpha_{2}=\right.$ $\ldots=\alpha_{76}=0$ ), the unrestricted model $(1)$ is estimated along with the restricted model (3), and the F-test is used to compare the resulting error sum of squares.

Table 3 contains the resulting F-statistic, which is significant at the 5 percent level. Therefore, we reject the null hypothesis and conclude that the intercepts of the 76 counties are not all the same. This means that there are county effects not included in the independent variables that affect the pull factors; model (1) is preferable to model (3). Similarly, model (1) is tested against model (2), which includes both county and time effects. The results (Table 3) indicate that there are time effects not captured by the set of independent variables, and therefore model (2) is the most appropriate model. Both county and time effects are statistically significant in explaining pull factors, and omission of either effect would cause the estimated coefficients to be biased. However, the county effects are more important than the time effects, possibly due to the short study period.

TABLE 3

County and Time Effects

Testing Altemative Models:

Model (1) vs. Model (3)

$F(75,375)=43.5$

Model (2) vs. Model (1)

$F(6,370)=8.80$

Time Effects, Model (2):

$\begin{array}{lll}\text { Period } & 1984 & .05467 \\ & 1985 & .03557 \\ & 1986 & -.0113 \\ & 1987 & -.0220 \\ & 1988 & -.0282 \\ & 1989 & -.0287\end{array}$


The results with respect to the independent variables are generally consistent with expectations. Demand factors play a central role in trade capture among rural Ilinois counties. The coefficients of the demand variables, per capita income, population, and unemployment rate, are statistically significant at the 5 percent level in model (2).

To examine the relative magnitudes of the coefficients, the "elasticity" of the pull factor with respect to each demand variable is calculated. ${ }^{7}$ Population is the most influential demand variable, followed by per capita income and unemployment rate. Population and per capita income are positively related to pull factors, with elasticities of .63 and .4, respectively. Unemployment rate is negatively and significantly related to pull factor, with a 1 percent rise resulting in a decline of .15 percent in the pull factor. Unemployed residents have low current incomes and uncertain future incomes, probably causing them to curtail retail purchases.

The results for the supply variables, number of retail stores and regional discount stores, are mixed. Retail stores are positively related to pull factor, although the coefficient is statistically insignificant in model (2). The coefficient is also very small, indicating that an increase of one retail outlet is associated with an increase in the pull factor of only .0003 . It may be that the number of stores does not represent the attractiveness of the county as a shopping destination.

The number of regional discount stores is positively and significantly related to pull factors at the .07 level. An additional discount store increases the pull factor by approximately .03 , suggesting that discount stores have a far greater impact on pull factors than other retail outlets. This measure of discount stores may not have been precise enough to capture the full impact of regional discount stores. Other measures (such as square footage) may be preferable, particularly since several discount chains are actively expanding and renovating existing stores. Furthermore, the proximity of competing discount stores may affect the capacity of a regional discount store to attract neighboring residents.

County effects explain a large share of the total variation in pull factors (model 1 versus model 3). Many structural elements, such as transportation access to neighboring cities and existing shopping center development, are embedded in the county effects. Structural elements are likely important to rural Illinois trade.

The lower portion of Table 3 presents the time effects for each year. Time effects show the amount by which the pull factor in each respective year deviates from the average after controlling for county effects and the independent variables. The time effects decline over the study period, suggesting an erosion in pull factors over time not explained by demand and supply changes. Although the evidence is limited by the short time period, it does suggest that structural changes, such as decreasing transportation costs and expanding urban shopping centers, are weakening the competitive position of rural trade. 


\section{CONCLUSIONS}

This study examines the determinants of retail trade capture in nonmetropolitan counties in Illinois using pooled time series and cross-section data from 1984 to 1989. By controlling for fixed effects, the approach avoids misspecification, while revealing trade patterns through time. Furthermore, the approach measures the strength of demand and structural elements affecting rural trade.

The findings indicate that demand is a major determinant of trade capture among rural Illinois counties. Retail trade will not prosper in rural counties unless population and income levels are maintained or expanded. Supply variables are not as influential, although there is some evidence that regional discount stores have an impact on trade capture.

However, explanatory variables explain only 41 percent, while other county and time effects account for 54 percent of the explained variation. This suggests that structural factors, such as access to neighboring cities, transportation costs, and prevailing shopping patterns, are critical in determining trade capture. Furthermore, there is evidence that these factors are changing over time to the detriment of rural areas. Rural merchants face competitive pressures from an expanding array of retail outlets including shopping centers, discount stores, and mail-order houses. Improvements in transportation, communication, and technology make these outlets more accessible to rural residents.

The findings suggest that policy to revitalize rural trade must consider both demand and structural factors. Since demand is important, broad-based economic development efforts to improve rural jobs and income are essential to the retail sector. However, since structural changes are reducing rural competitiveness, other policy measures may be necessary. For example, technical assistance to rural merchants may improve their competitiveness in a complex, changing environment. However, future research requires examination of longer time periods than was available in this study.

\section{ENDNOTES}

1. This calculation of pull factor uses downstate per capita expenditures. Since per capita sales are much higher in the Chicago Consolidated Metropolitan Statistical Area (CMSA), the downstate figure represents expenditure levels in rural counties more accurately than state per capita expenditures. 
This measure of the pull factor omits the relative income component. Instead, following Yanagida et al. (1991), relative income is included as an independent variable.

2. This is clearer if the pull factor equation is written as the ratio of per capita sales in community $i$ to downstate per capita sales, that is

$$
\mathrm{PFi}_{i}=\frac{\frac{\text { SALES }_{i}}{P O P_{i}}}{\frac{\text { SSALES }}{S P O P}}
$$

where $\mathrm{PF}_{\mathrm{i}}=$ pull factor for community $\mathrm{i}$

$$
\begin{aligned}
& \text { SALES }_{i}=\text { total retail sales in community } i \text {, } \\
& \text { POP } i=\text { population of community } i \\
& \text { SSALES }=\text { downstate per capita sales, } \\
& \text { SPOP }=\text { downstate population. }
\end{aligned}
$$

Demand affects pull factors to the extent that local residents reduce (increase) per capita spending below (above) that of the downstate average.

3. A difficulty with the least-squares procedure is that the assumption of constant intercept is often unreasonable.

4. If the slopes were to vary as well, each separate cross-section regression would involve a distinct model, and pooling would be inappropriate. To test the assumption that all cross-sectional units have the same slope, the regression coefficients are estimated separately for each cross section. However, our sample has only six observations for each county, and this test cannot be performed.

5. Another method to deal with Equation (2) is to treat $\alpha_{i}$ and $\gamma_{t}$ as random. This is known as the random effects or error component model, where the regression error is assumed to have three components: one for time, one for cross section, and one as a combination of both.

6. An important issue is whether the dummy variables are fixed, as the fixed effects model assumes, or random. In the latter case, a random effects or error components model should be used. The random effects model is appealing because it is less costly in degrees of freedom, resulting in more efficient estimates compared to the fixed effects model. However, the random effects model assumes that the county effects are uncorrelated with the other regressors. The advantage of the fixed effects model is that it protects us from a specification error caused by correlation between the counties and the explanatory variables. 
Hausman's (1978) chi-squared statistic test, with a value of 57.68, indicates that there is correlation between the counties and the independent variables. Therefore, the fixed effects model is more appropriate than the random effects model. Furthermore, the present study uses the population of nonmetropolitan counties, rather than a sample, as the random effects model assumes.

7. Elasticity is defined as the percent change in pull factor in response to a 1 percent change in the value of each demand variable calculated at mean values from model (2).

\section{REFERENCES}

Blair, John P. Urban and Regional Economics. Homewood, Ill.: Richard D. Irwin, Inc., 1991.

Christaller, Walter. "Die Zentralen Orte in Suddeutschland." Jena, Germany:

Fisher, 1933. English translation by C. Baskin. The Central Places of

Southern Germany. Englewood Cliffs, N.J.: Prentice-Hall, 1966.

Darling, David L., and Jin-Song Tan. "Retail Trade Patterns of Rural Kansas."

Choices (Second Quarter 1990): 34-35.

Hausman, J. "Specification Tests in Econometrics." Econometrica 46 (1978): 1251-1271.

Hustedde, Ron, Ron Shaffer, and Glen Pulver. Community Economic Analysis: A How to Manual. Ames: North Central Regional Center for Rural Development, Iowa State University, 1984.

Illinois Department of Revenue. "Kind of Business 360 Reports." Springfield, Illinois, various years.

Love, J. L. "Local Sales Tax Options: A Case Study of South Georgia." The Review of Regional Studies 22 (1992): 105-114.

Nerlove, Mark. "Further Evidence of Dynamic Economic Relations From a Time-

Series of Cross-Sections." Econometrica 39 (1971): 359-89.

Schneider, Mark. "City Limits and the Growth of Suburban Retail Trade, 19821987." Urban Affairs Quarterly 27 (1992): 604-614.

Senf, David R. "Shift-Share Analysis of Rural Retail Trade Patterns." Regional Science Perspectives 18 (1988): 29-37.

Snodgrass, Dodd W., and Daniel M. Otto. "Analysis of Local Taxation in Rural Areas: An Oklahoma Case Study." Growth and Change 21 (1990): 34-45.

Stone, Kenneth. "The Impact of Wal-Mart Stores on Retail Trade Areas in Iowa." Manuscript, 1989.

U.S. Council of Economic Advisors. Economic Report of the President. Washington, D.C.: Govemment Printing Office, 1992. 
Walsh, Michael, and Jonathan D. Jones. "More Evidence on the 'Border Tax' Effect: The Case of West Virginia, 1979-84." National Tax Journal 41 (1988): 591-601.

Walzer, Norman, and Ralph Stablein. "Small Towns and Regional Centers." Growth and Change 12 (1981): 2-8.

Yanagida, John F., Bruce B. Johnson, Joel Young, and Michael Lundeen. "An Analysis of Economic and Noneconomic Factors Affecting Retail Sales Leakages." The Review of Regional Studies 21 (1991): 53-64. 